\title{
Assistência Técnica e Extensão Rural em comunidades rurais do sul do Amazonas
}

\section{Technical Assistance and Rural Extension in rural communities of the south of Amazonas}

Marcia Campos Gomes - Mestra em Extensão Rural pela Universidade Federal de Viçosa (UFV). E-mail: marciia.mcg@gmail.com

Ana Claudia Fernandes Nogueira - Doutoranda no PPG em Sociologia, pela UFGRS. Professora da Universidade Federal do Amazonas (UFAM) e membro do Núcleo de Pesquisa e Extensão em Ambiente, Socioeconomia e Agroecologia (NUPEAS). E-mail: anamanaus@gmail.com

Francimara Souza da Costa - Doutora em Ciências Socioambientais pelo NAEA/UFPA. Mestra em Aquicultura em Águas Continentais pela Universidade Estadual Paulista. Professora da Universidade Federal do Amazonas (UFAM). E-mail: francimaracosta@ yahoo.com.br

\section{Resumo}

Os serviços de ATER no Brasil auxiliam os produtores rurais na melhoria de seus sistemas produtivos, orientados pela política nacional (PNATER). Este artigo tem por objetivo analisar a execução da PNATER em comunidades rurais localizadas no sul do estado do Amazonas. A metodologia proposta é de cunho qualitativoquantitativo, tendo como base analítica a análise de conteúdo, e a utilização de dados socioeconômicos dos agricultores tabulados no programa de estatística SPSS. Foram utilizados também dados de campo recolhidos por meio de entrevistas semi-estruturadas e DRP. De posse de um quadro analítico, verificou-se que o serviço de ATER é escasso em grande parte dos estabelecimentos rurais da região analisada. Reconhece-se que a implantação de uma política de ATER voltada à agricultura familiar em modos ambientalmente sustentáveis de produção é limitada, em consequência do baixo investimento no estado do Amazonas em ações de ATER. Concorre ainda a herança difusionista do antigo modelo e do limitado conhecimento dos técnicos sobre a nova política, além da falta de alcance a novas tecnologias sociais por parte dos(as) agricultores(as).

\section{Palavras-chave}

Política Pública. Agricultura Familiar. Assentamento. PNATER.

\begin{abstract}
This article aims to analyze the execution of PNATER in rural communities located in the southern state of Amazonas. The proposed methodology is qualitative-quantitative, based on analytical content analysis (BARDIN, 2007), and socioeconomic data of farmers tabulated in the SPSS statistical program; Field data collected through semi-structured interviews and PRA. With an analytical framework it was found that the ATER service is scarce in most rural establishments. It is recognized that the implementation of an ATER policy aimed at family agriculture and environmentally sustainable modes of production is limited as a consequence of the low investment of the state of Amazonas in actions of ATER, still the diffusionist heritage of the old model and the limited knowledge of the technicians on The new policy, and the lack of access to new social technologies for farmers.
\end{abstract}

\section{Keywords}

Public Policy. Family Farming. Settlement. PNATER. 


\section{INTRODUÇÃO}

O modelo clássico de extensão rural institucionalizada foi exercido com base na ideia de que o conhecimento tecnológico, a difusão de novas técnicas agropecuárias e o apoio financeiro por meio do crédito contribuiriam para o aumento da produção e para a melhoria das condições de vida do meio rural. Este paradigma se manteve no Brasil até a abertura democrática e a Constituição de 1988, o que pode ser identificado no apoio dado pelo Sistema Brasileiro Descentralizado de Assistência Técnica e Extensão Rural (SIBRATER). No texto do primeiro Plano Nacional de Reforma Agrária é observada a menção ao incentivo a um modelo de desenvolvimento rural mais justo e ambientalmente equilibrado nos assentamentos da reforma agrária. Nesse contexto, a organização dos movimentos sociais ligados ao campo travou lutas e mobilizações com vistas a uma ATER menos difusionista, mais participativa e inclusiva na agricultura familiar, o que se tornou mais emblemático a partir dos anos de 1990 na luta contra diversas tentativas de desmonte da ATER no Brasil:

nos anos 90 o Movimento dos Sem-Terra e o movimento sindical de trabalhadores rurais (organizados na Confederação Nacional de Trabalhadores da Agricultura - CONTAG) desenvolveram ações que legitimavam politicamente estudos acadêmicos que propunham uma nova categoria de análise: o de agricultor familiar. O conceito de agricultura familiar influenciaria as políticas públicas no restante dos anos 90, com a intensificação das ações de Reforma Agrária e de fortalecimento dessa categoria de produtores rurais (PEIXOTO, 2008, p. 30).

Os avanços no debate ampliado sobre uma política nacional de ATER, aliados à organização dos movimentos sociais e a uma mudança de orientação voltada a uma política de Estado, possibilitaram a elaboração da primeira Política Nacional de Assistência Técnica e Extensão Rural para a Agricultura Familiar em 2001. Durante o ano de 2003, o Ministério do Desenvolvimento Agrário (MDA) promoveu um debate mais ampliado e democrático, formulando uma nova proposta do que é hoje a Política Nacional de Assistência Técnica e Extensão Rural (PNATER), que permitiu a elaboração das diretrizes do Programa Nacional de Assistência Técnica e Extensão Rural (PRONATER). Os serviços de ATER expressos por meio da PNATER estabelecem como missão:

Participar na promoção e animação de processos capazes de contribuir para a construção e execução de estratégias de desenvolvimento sustentável, centrado na expansão e fortalecimento da agricultura familiar e das suas organizações, por meio de metodologias educativas e participativas, 
integradas às dinâmicas locais, buscando viabilizar as condições para o exercício da cidadania e a melhoria da qualidade de vida da sociedade (BRASIL, 2004, p. 9).

Nesta ordem, compreende-se que as instituições que prestam assistência técnica e extensão rural deveriam ter como missão atender as necessidades da agricultura familiar, compartilhando conhecimentos tecnológicos, por meio da aplicação de uma metodologia diferenciada, tendo um enfoque construtivista para cada realidade encontrada no meio rural, buscando a eficiência produtiva e a melhoria da qualidade de vida das famílias que vivem em áreas rurais (CASTRO, 2005). A política pública de assistência técnica e extensão rural contribuiria, portanto, para uma ação institucional que possibilitaria a implantação e a consolidação de estratégias sustentáveis de desenvolvimento rural, capazes de gerar renda e novos postos de trabalho. Destacam-se como eixos norteadores da política: as bases epistemológicas da agroecologia, o respeito à pluralidade e à diversidade social, econômica, étnica, cultural e ambiental do país, o que implica na necessidade de se incluírem enfoques de gênero, de geração, de raça e de etnia nas orientações de projetos e programas (CASTRO, 2005).

Em virtude do exposto, a realização desta pesquisa surgiu a partir das experiências e de um levantamento de dados do Núcleo de Pesquisa e Extensão em Ambiente, Socioeconomia e Agroecologia (NUPEAS), da Universidade Federal do Amazonas (UFAM), Campus Humaitá, que apontavam para uma realidade fragilizada em suas condições materiais de existência e relativa falta de ações de ATER em comunidades rurais do sul do estado do Amazonas. Diante da realidade rural local, percebeu-se a necessidade de estudos relacionados não somente ao fornecimento dos serviços de ATER, mas também compreender como o Amazonas tem buscado inserir-se nas ações sugeridas na PNATER. Buscou-se assim explorar pesquisas que envolvam a realidade da agricultura familiar no Amazonas no intuito de produzir informações sobre esta prestação de serviço, trazendo subsídios a órgãos públicos, organizações sociais e a seu principal beneficiário, o agricultor familiar. É necessário um entendimento mais amplo da política de ATER voltada à agricultura familiar brasileira, principalmente em função do aspecto da interação e da participação direta desses atores nas ações e seus devidos resultados.

Com a nova percepção socioambiental da sociedade e a cobrança por medidas e ações sustentáveis no cumprimento dos compromissos, os desafios propostos pela PNATER são considerados propícios. Os desafios que deverão ser superados, de acordo com a política, tendem a caminhar no sentido favorável ao desenvolvimento sustentável, desde que sejam aplicados na prática, possibilitando 
o atendimento a todos aqueles que estão nas áreas rurais (MEDEIROS, 2012).

Levando em consideração os princípios e as diretrizes da política de ATER que surgem frente às crises econômicas e socioambientais ocorridas no país, a implementação de estratégias ambientais e socialmente sustentáveis de produção torna-se importante, pois as famílias rurais envolvidas neste processo possuem uma diversidade de práticas que se aproximam ou distanciam de ações autóctones, de acordo com o tipo de assistência e extensão que recebem. Desta forma, esta pesquisa objetivou analisar a execução da PNATER em comunidades localizadas no sul do Amazonas, bem como as condições estruturais do Instituto de Desenvolvimento Agropecuário e Florestal do Amazonas (IDAM) que atende estas comunidades com serviços públicos de ATER.

\section{PROCEDIMENTOS METODOLÓGICOS}

Este estudo foi realizado nas comunidades Setor Três Estados (assentamento Juma), município de Apuí e assentamento São Francisco, sul do município de Canutama, que são projetos de assentamento da reforma agrária no estado do Amazonas. O universo pesquisado diz respeito a agricultores(as) familiares das localidades acima mencionadas e técnicos das agências que prestam serviços nesses locais.

Em busca de uma melhor compreensão sobre quem são e o que fazem os(as) agricultores(as) foi necessária a construção de um perfil socioeconômico e de produção, a partir do Banco de dados do NUPEAS já organizado na plataforma SPSS, onde foram analisados dados de 53 (cinquenta e três) agricultores(as) familiares, sendo 30 (trinta) no Setor Três Estados e 23 (vinte e três) do assentamento São Francisco. Para verificar as condições da agência de ATER no sul do Amazonas foram entrevistados três funcionários (gerentes regionais) dos escritórios de ATER localizados nos municípios de Humaitá, Apuí e Canutama. O município de Humaitá foi inserido nas entrevistas das unidades locais de ATER por ter fornecido os serviços de ATER no assentamento São Francisco até o ano de 2011.

\section{1 ÁREA DA PESQUISA}

No município de Apuí a área analisada se refere ao setor Três Estados que compreende as vicinais Três Estados, Três Buritis, Três de Julho, Cupuaçu e Linhares e está localizado a $54 \mathrm{~km}$ da sede do município e tem como principal via de acesso a rodovia BR-230 (Transamazônica). O setor é constituído por 
aproximadamente 110 famílias. A principal atividade econômica na área é a agricultura de base familiar voltada principalmente para os cultivos das culturas do café (Coffea canephora) e guaraná (Paullinia cupana Kunth). No entanto, os moradores também desempenham atividades voltadas para criação animal com destaque principalmente para o gado leiteiro e de corte.

A outra área estudada foi o assentamento São Francisco, localizado a dezoito horas de voadeira (barco com motor) até o município de Lábrea e mais oito horas via fluvial até a sede do município de Canutama, com acesso terrestre à cidade de Porto Velho (RO) pela rodovia BR-319, numa distância de setenta quilômetros. O assentamento é constituído por 259 famílias assentadas, contabilizando um número de aproximadamente 200 famílias residentes, tendo como principal atividade econômica a agricultura familiar voltada para os cultivos da cultura da mandioca (Manihot esculenta Crantz), cupuaçu (Theobroma grandiflorum), guaraná (Paullinia cupana Kunth) e urucum (Bixa orellana).

\subsection{TÉCNICA DE COLETA E ANÁLISE DE DADOS}

Em decorrência de ter como um dos focos a execução local da PNATER, optou-se como estratégia metodológica uma abordagem de cunho quantiqualitativo. Os dados utilizados para análise qualitativa foram as entrevistas semiestruturadas e o Diagnóstico Rápido Participativo (DRP). Os dados utilizados para análise quantitativa foram: variáveis do banco de dados do NUPEAS referentes ao gênero, idade, escolaridade, fonte de renda, titularidade da propriedade, principais culturas cultivadas e para quem são vendidos os produtos produzidos. Esses dados foram tabulados e avaliados a partir da plataforma SPSS.

As entrevistas semiestruturadas foram realizadas com os representantes das unidades locais de ATER. As questões foram abertas e fechadas e totalizavam trinta e três questões relacionadas às estruturas dos órgãos que realizam assistência técnica e extensão no sul do Amazonas, especificamente nos municípios de Apuí, Canutama e Humaitá, bem como a avaliação e a compreensão que os mesmos possuíam da PNATER. A entrevista teve ainda por finalidade averiguar como estão estruturadas as unidades locais, trazendo questões voltadas a condições de infraestrutura, logística e equipe técnica de cada unidade local, além de questões avaliativas sobre a PNATER. Vale ressaltar que todos os entrevistados participantes deste estudo assinaram o Termo de Consentimento Livre e Esclarecido (TCLE) concordando com a realização do mesmo, optando-se por não identificá-los nominalmente. 
O DRP foi realizado junto aos(às) agricultores(as) das comunidades envolvidas na pesquisa (Figura 1). Optou-se por essa técnica por compreender que o "DRP é uma ferramenta que permite que as comunidades façam o seu próprio diagnóstico e a partir daí comecem a autogerenciar o seu planejamento e desenvolvimento" (VERDEJO, 2006, p. 6). Assim sendo, o DRP foi utilizado como instrumento da coleta de dados, principalmente por ser uma ferramenta que não pretende apenas coletar dados dos participantes, mas também auxiliar para que estes iniciem um processo de autorreflexão dos próprios problemas enfrentados e possibilidades para solucioná-los (VERDEJO, 2006).

Figura 1 - Aplicação do DRP no assentamento São Francisco/Canutama

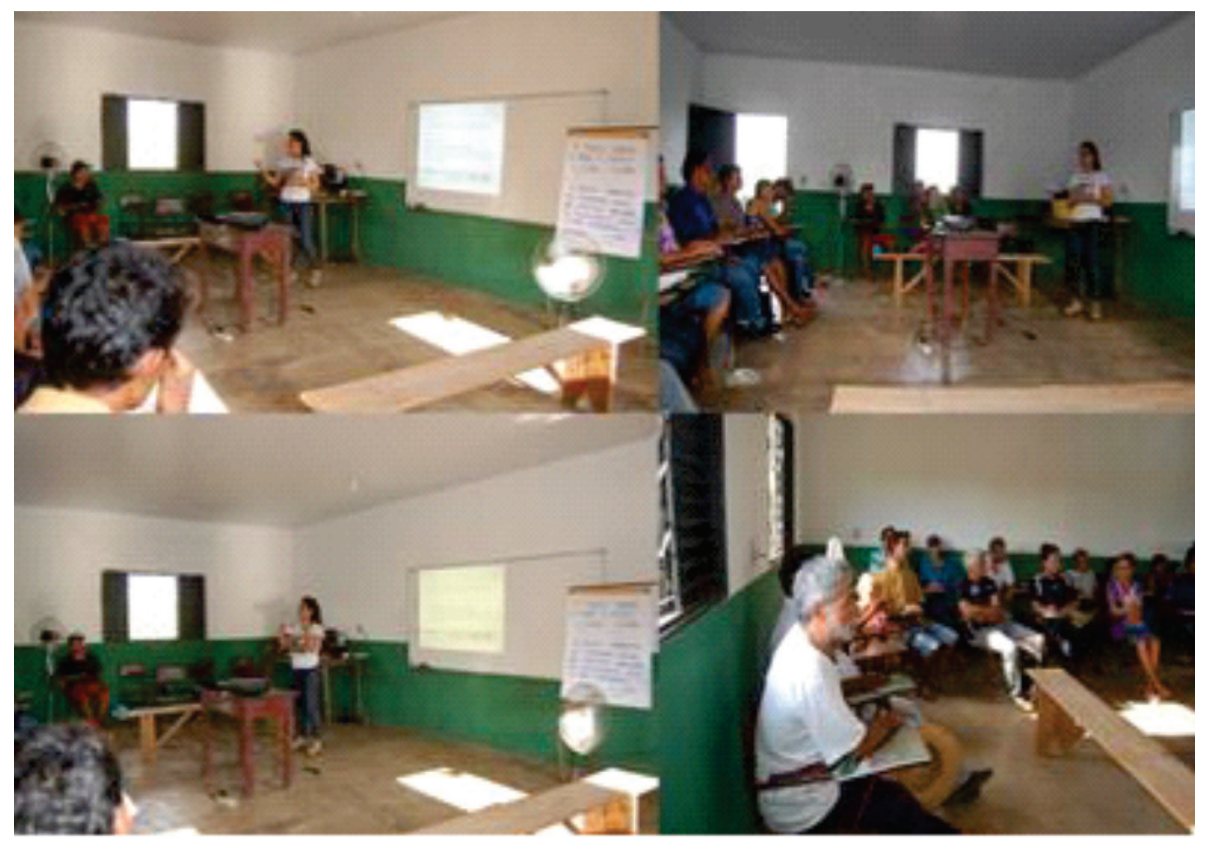

Fonte: NUPEAS (2013)

Para a aplicação do DRP nas comunidades foi realizado um contato prévio com lideranças locais em busca de apoio para a pesquisa, encaixando as ações de campo às agendas das associações e dos(as) agricultores(as). Assim, não os tiraríamos de suas rotinas e também nos beneficiaríamos de suas atividades coletivas já planejadas. Desta forma, expusemos aos participantes da pesquisa a natureza do trabalho, abrindo em seguida o debate e a discussão sobre a participação deles ou não. Depois de um interesse coletivo e participativo informamos que os representantes das associações assinariam um termo de anuência onde firmamos em conjunto o compromisso com a realização da pesquisa. 
Na realização do DRP o total de participantes no Setor Três Estados foi de 16 (dezesseis) pessoas, sendo 14 (quatorze) homens e 2 (duas) mulheres. $\mathrm{Na}$ comunidade São Francisco foi um total de 35 (trinta e cinco) pessoas onde 24 (vinte e quatro) eram homens e 11 (onze) mulheres. Portanto, o DRP foi aplicado para uma amostra de 51 (cinquenta e um) agricultores nas duas comunidades estudadas. Objetivando reunir as informações coletadas por meio do DRP traçouse um perfil socioeconômico e produtivo das comunidades estudadas utilizandose o Banco de Dados do NUPEAS que estavam tabulados na plataforma SPSS, além de referências de informações de campo e revisão bibliográfica sobre a temática proposta:

Somando-se as técnicas de coleta, os dados foram tratados, tabulados, sistematizados e analisados à luz da Análise de Conteúdo (BARDIN, 2007). Esta permitiu a construção de quadros analíticos a partir de questões chaves postas como problematizadoras tanto nas entrevistas quanto no DRP, criadas por meio de palavras ou expressões presentes nos discursos dos técnicos e dos(as) agricultores(as), onde o tema central era o serviço de ATER.

\section{RESULTADOS E DISCUSSÕES}

2.1 CONDIÇÕES SOCIAIS, ECONÔMICAS E DE PRODUÇÃO DAS COMUNIDADES SETOR TRÊS ESTADOS (APUÍ), E PROJETO DE ASSENTAMENTO SÃO FRANCISCO (CANUTAMA)

As comunidades estudadas apresentam como perfil agricultores(as) que, em sua maioria, migraram para as terras amazônicas em busca de novos objetivos, sendo predominante no Setor Três Estados, município de Apuí, a vinda de pessoas da região sudeste, especificamente dos estados do Espírito Santo e de Minas Gerais. No assentamento São Francisco as origens dividem-se entre as regiões Norte e Nordeste, de estados como Rondônia, Mato Grosso, Paraíba, Pernambuco, Piauí e Maranhão. Assim, o processo de migração para o Amazonas pode ser configurado a partir de uma dinâmica externa, com a vinda de indivíduos de outros estados e regiões; e interna com a ocupação dos espaços, disponibilizados pelas políticas de reforma agrária, por indivíduos nativos oriundos de calhas de diferentes de rios. O que nos permite inferir que a migração do agricultor familiar para terras amazônicas baseou-se principalmente na busca por expectativas de uma vida melhor, sendo este participante do processo de ocupação da região. 
Neste universo composto por uma diversidade sociocultural a população que fez parte desta pesquisa constitui-se em 75,5\% dos agricultores do gênero masculino e $24,5 \%$ do gênero feminino, onde $66 \%$ possuem idade média acima de 40 anos, sendo que 22,6\% estão entre 30 e 40 anos e 11,3\% entre 18 e 30 anos de idade. Os dados sobre faixa etária apontam que há uma escassez de uma população mais jovem no trabalho e na vida rural, dificultando o trabalho na agricultura e a reprodução do modo de produção familiar. Este cenário demonstra o caráter de urgência no estabelecimento de políticas voltadas a conquistar a retomada dos jovens às suas comunidades, uma vez que preferem ir para as áreas urbanas em busca de oportunidades, como emprego, lazer e melhores condições de educação e saúde.

$\mathrm{O}$ acesso a educação e equipamentos sociais que permitam que as populações rurais sejam incluídas nos processos de mudança e tenham acesso às mesmas tecnologias disponíveis às populações urbanas ainda é um mito no Brasil. A condição de abandono estrutural e social impõe que o campo seja um lugar sem atrativos para as jovens populações e lhes condicionar um ciclo de fuga contínuo. A educação dos trabalhadores rurais, por exemplo, é um elemento crucial para melhoria da capacidade de uso eficiente dos recursos disponíveis e, portanto, aumento na renda desta população (SCHULTZ, 1964). Mas as condições com que nos deparamos revelam uma baixa escolaridade onde 11,3\% dos entrevistados não sabem ler, 7,5\% lê e escreve pouco, 58,5\% não completaram o ensino fundamental, $17 \%$ possui o ensino fundamental completo, e somente $3,8 \%$ possui ensino médio completo e $1,9 \%$ possuem superior completo, sendo este último referente aos professores das escolas rurais.

Diante deste quadro e das observações realizadas verifica-se que as condições de educação são insuficientes, pois além da maioria dos agricultores possuírem somente o ensino fundamental, há também um índice significativo de analfabetismo e analfabetismo funcional. De acordo com Neiva (2009), os índices de escolaridade nas comunidades rurais de todo o país ainda são muito baixos. Para Costa (2014), esses baixos índices educacionais em comunidades rurais estão atrelados a uma série de fatores dentre eles as condições precárias de infraestrutura das escolas, a qualificação insuficiente dos professores e a alta rotatividade desses profissionais (uma vez que a maioria é da área urbana e, quando possuem oportunidade, querem voltar para a cidade). Concorrem também para esse quadro a ausência de biblioteca e recursos eletrônicos, a precariedade de energia elétrica, além da ausência de um abastecimento adequado de água e as péssimas condições sanitárias das escolas. 
Melhorar o nível educacional formal dos agricultores é questão unânime para os estudiosos nesta área, não somente pela garantia constitucional do acesso à educação formal, mas também por permitir de maneira mais rápida e fácil o acesso a novas tecnologias, ou mesmo o aprimoramento das tecnologias já existentes. Além de ser importante estratégia para cultivar os jovens nas comunidades rurais e consequentemente na agricultura familiar, reproduzindo assim o conhecimento passado de pai para filho. O direito à educação também é um importante instrumento de geração de renda, e este promove autonomia e empoderamento das populações que vivem nas zonas rurais.

A agricultura representa $75,5 \%$ da principal renda das famílias entrevistadas, contra $25,5 \%$ de outras fontes (pecuária, piscicultura, funcionalismo público e autônomos com 33,9\%; bolsa/benefício 26,4\%; aposentadoria 16,9\%, extrativismo 1,9\%; e comércio 1,9\%). Mesmo sendo a principal fonte de renda, a agricultura gera somente até um salário mínimo e meio para mais de $80 \%$ dos entrevistados. A diversidade de atividades realizadas nas comunidades rurais na Amazônia (COSTA, 2014) não garante acesso a bens e serviços, uma vez que o valor gerado ao final de uma safra atende somente as necessidades básicas de consumo daquilo que não é autoproduzido.

A ausência de serviços básicos também se estende a garantias fundiárias, mesmo os entrevistados residindo em área de assentamento da reforma agrária. Ainda que 84,9\% dos entrevistados se identifiquem como proprietários e somente $15,1 \%$ como não proprietários, mais de $60 \%$ dos entrevistados não possuem título definitivo. Este fato, no entanto, não retira o sentido de pertencimento dessas populações à "sua" terra, mas também demonstra um dado relevante que diz respeito à efetivação das políticas de reforma agrária, uma vez que de acordo com o tempo de residência destes entrevistados nestas comunidades é possível observar que 5,7\% estão com um (1) ano residindo na comunidade; $24,5 \%$ entre 1 (um) e 5 (cinco) anos; 26,4\% de 5 (cinco) a 10 (dez) anos; e 43,4\% mais de 10 (dez) anos de residência na comunidade. Como as áreas da pesquisa pertencem a assentamentos que foram criados há mais de 15 anos, percebe-se uma alta rotatividade de agricultores (mais de 50\%) que não foram assentados no primeiro momento.

Fazendo um paralelo com a condição de proprietário do lote e tempo de residência, o processo de titulação definitiva consiste na entrega dos documentos que atestem a propriedade do lote, quando o Instituto Nacional de Colonização e Reforma Agrária (INCRA) passa a não ser mais o guardião deste, e o lote passa ao regime de concessão de uso à família assentada. O termo de concessão de uso é inegociável até dez anos, a partir da emissão deste contrato. O título 
definitivo só pode ser emitido três anos após a matrícula definitiva no órgão federal responsável pelo assentamento (CORDEIRO, 2011).

A agricultura familiar na Amazônia caracteriza-se como uma importante forma de organização da produção que associa família, produção e trabalho nos diversos ambientes de produção terrestre e aquáticos. Os critérios utilizados pelos agricultores amazônicos para direcionar as decisões relativas às atividades agrícolas na agricultura familiar não visam apenas rentabilidade, mas principalmente atender as necessidades básicas da família. Os agricultores familiares amazônicos se caracterizam por exercerem uma pluralidade de atividades produtivas que são fundamentais para complementar seus rendimentos e suas necessidades de sobrevivência (FRAXE; PEREIRA; WITKOSKI, 2011).

Para Fraxe, Pereira e Witkoski (2011), a agricultura na Amazônia é baseada em sua maioria, na unidade de produção assentada na mão-de-obra familiar. Para compreender os aspectos socioeconômicos da agricultura familiar é necessário conhecê-los e relacioná-los aos tipos de famílias existentes. Portanto, com relação à mão-de-obra nas unidades familiares, verificou-se que em todas elas a família é responsável por todas as atividades praticadas, o que não impossibilita a contratação de mão-de-obra externa à família (41,6\%), principalmente nas atividades de colheita das culturas. A organização dessas atividades é realizada pelos grupos familiares ou por mutirão, que consiste na ajuda mútua dos comunitários para execução de alguma tarefa, é uma prática realizada por alguns(as) agricultores(as) e são organizadas de acordo com a necessidade de cada família. Assim sendo, é importante enfatizar que composição da família é um fator importante no trabalho do campo.

Quando levantados os dados de produção nas áreas de estudo, identificamos que no Setor Três Estados a cultura do café (Coffea canephora) e do guaraná (Paullinia cupana Kunth) são as principais, com 93,28 e 35,64 hectares plantados no ano de 2011, respectivamente, onde $87 \%$ dos entrevistados produzem café e $30 \%$ guaraná. Este perfil de produção ligado ao cultivo do café pode estar relacionado com o lugar de origem destes agricultores, já que a maior parte é oriunda do Sudeste, onde a cultura do café é tradicional. Esse quadro difere assim da maioria dos cultivos da Região Amazônica que estão voltados principalmente para a mandioca. O guaraná é uma cultura que vem se destacando na comunidade em razão de ser uma planta de grande importância econômica e social, especialmente na Amazônia, pois é um cultivo tradicional do estado. Com isso, Fraxe et al. (2008) descrevem o processo de adaptação à região com a troca de experiências e costumes trazidos de outras regiões, como exemplo as formas de plantio, alimentação e crenças. 
No assentamento São Francisco foi encontrado outro perfil de produção, voltado principalmente para o cultivo da mandioca (Manihot esculenta Crantz), cupuaçu (Theobroma grandiflorum) e guaraná (Paullinia cupana Kunth) com 20,16, 13,44 e 17,06 hectares plantados no ano de 2011. 56,2\% dos entrevistados nesta comunidade produzem mandioca, 30,4\% cupuaçu e 21,7\% guaraná. De acordo com os agricultores familiares, a principal finalidade do cultivo da mandioca é o consumo próprio e a comercialização, pois esta proporciona um grande ajuste na renda familiar. Corroborando assim com que afirma Fraxe (2004), que o destaque da mandioca se dá por ela ser um componente básico do sistema de produção na Amazônia, quer seja em ambientes de várzea, quanto nos ambientes de terra firme, em razão de sua dupla finalidade: subsistência e comercialização.

O guaraná e o cupuaçu possuem espaço bastante expressivo no assentamento São Francisco, pois o retorno econômico com essas culturas é maior segundo os entrevistados. Isto significa dizer que mesmo que a maioria dos agricultores da comunidade seja oriunda de outras regiões do país, eles aderiram ao modo de vida e de produção dos agricultores familiares da Amazônia, de acordo com as características ambientais e culturais do bioma amazônico. Fraxe, Pereira e Witkoski (2011) concordam com este fato, quando afirmam que o modo de vida dos agricultores familiares da Amazônia advém do conhecimento sobre os ecossistemas de várzea e terra firme, do uso e manejo dos recursos naturais da região, sendo este conhecimento adquirido por meio de um processo adaptativo e renovado do seu cotidiano e repassado pelas gerações.

Apesar de as áreas pesquisadas apresentarem perfis de produção diferenciados, foi possível levantar que a principal dificuldade apresentada tanto no Setor Três Estados quanto no assentamento São Francisco é a dificuldade de comercialização devido à falta de estradas, além de enfrentarem problemas com pragas e doenças que também limitam a produção de maneira significativa, e ausência de serviços de ATER.

Nestas comunidades, a comercialização dos produtos é feita por meio de uma malha de agentes econômicos (atravessador 45,3\%, comerciantes 24,5\%), na própria comunidade $(3,8 \%)$, em feira local $(3,8 \%)$ e outros $(5,7 \%))$. Dessa forma, o agente mais abrangente nas duas comunidades é o atravessador, que por sua vez proporciona um aumento no preço dos produtos ao consumidor final e a queda do capital monetário recebido pelos produtos dos agricultores familiares (MATOS; MARIN, 2009).

De acordo com Oliveira e Mayorga (2005), os atravessadores são agentes de comercialização que atuam nas cadeias produtivas como intermediários, nas comercializações dos produtos independente da origem, entre os produtores 
e os consumidores. Estes atravessadores aproveitam-se da desorganização e da desestruturação dos agricultores, principalmente daqueles que praticam a comercialização de forma individual, para adquirir seus produtos a um preço extremamente baixo, sob pena da perda pela deterioração dos mesmos, e revendendo-os ao atacado ou varejo a preços determinados pelo próprio atravessador, pelo fato da concentração dos produtos, aumentando dessa forma seu poder de negociação com os clientes.

Nas duas áreas pesquisadas observou-se o enfraquecimento dos modos de associações existentes. Apesar das famílias estarem organizadas por meio de associações comunitárias, notou-se que estas ainda não possuem uma solidificação enquanto unidade de mobilização e organização social. Devido a este problema, ocorre a venda individual dos produtos e a ausência de crédito nas práticas associativistas é atribuída principalmente à falta de organização social e produtiva. Observa-se que fatores como problemas de infraestrutura para o escoamento da produção, falta de organização social e descrédito nas práticas associativistas vêm distanciando esses agricultores dos mercados compradores, sendo, portanto, necessário trabalhar o fortalecimento das práticas associativistas para comercialização coletiva nestas localidades.

Considerando a quantidade de produção normalmente obtida por um agricultor familiar, é difícil que, sozinho, detenha ou domine as condições que se fazem necessárias para que consiga superar a dependência em relação ao atravessador. Para a maioria dos agricultores familiares, um dos únicos caminhos para desenvolver um mínimo de autonomia na comercialização de sua produção é criar um processo de vendas em coletivo (COSTA, 2004).

\subsection{A PNATER EM COMUNIDADES RURAIS DO SUL DO ESTADO DO AMAZONAS: UMA AMOSTRAGEM}

Com o surgimento da PNATER e com ela um novo modelo e perfil de ATER, Caporal (2005) afirma que a partir da implementação dessa lei há uma exigência maior no amplo processo de formação de profissionais de ATER com um perfil voltado a um caráter mais educativo. Neste sentido, para Pettan (2005), o extensionista constitui-se no elemento-chave do serviço de extensão rural, tal como um missionário, é nele que se concentra toda a atenção do sistema, pois de sua atuação depende em grande parte o êxito ou o fracasso dos serviços realizados. Para este novo agente de extensão o produtor rural não é somente o agricultor, mas, também, sua esposa e seus filhos, uma vez que todos exercem funções importantes no trabalho cotidiano da unidade de produção familiar. 
Diante do exposto, tornou-se imprescindível nesta pesquisa, saber a avaliação dos órgãos locais de ATER sobre a PNATER. Nesta avaliação, as respostas foram bastante confusas e vagas como, por exemplo, "a política é normal'. As respostas evasivas levaram a deduzir que há pouca informação quanto ao assunto, de forma que esta falta de conhecimento, além de impossibilitar uma futura readequação da proposta nacional de ATER, tende a atrapalhar a execução desta por meio das chamadas públicas, inviabilizando também a construção de uma política estadual de ATER orientada de forma a preconizar novos enfoques metodológicos e incentivando a agroecologia e produção orgânica, sugeridas como novos paradigmas tecnológicos para o desenvolvimento rural sustentável.

Para Pettan (2005), a inovação da PNATER diz respeito à pluralidade e às diversidades sociais, econômicas, étnicas, culturais e ambientais do meio rural brasileiro, permitindo e estimulando desta forma que os profissionais de ATER executem suas ações junto à agricultura familiar mediante o uso de metodologias participativas, desempenhando um papel educativo dentro do processo de desenvolvimento rural sustentável. Neste sentido, podemos aferir que se não é possível observar a pactuação dos órgãos locais com a PNATER, consequentemente haverá também um distanciamento entre esta e os agricultores familiares que são seus principais beneficiários.

Prova disto é o resultado da pesquisa realizada nas localidades estudadas, pois de acordo com as questões respondidas no DRP realizado no Setor Três Estados e na comunidade São Francisco, foi possível identificar que os agricultores desconhecem a PNATER e mais, que alguns confundem o real papel do órgão local de ATER, chegando a achar que o mesmo é responsável pela abertura de estradas. Contudo, estas respostas não surpreenderam por completo, haja vista que as respostas das unidades locais de ATER estavam voltadas para uma definição de extensão e assistência técnica ainda nos moldes convencionais. Porque, por mais que tenham citado a assistência técnica como papel primordial do órgão, esta se perde quando são perguntados quais os serviços que eles oferecem aos beneficiários.

Os agricultores familiares das áreas estudadas, em sua maioria, informaram que praticamente não há serviço de ATER na sua localidade. Quando há esta se limita principalmente a reuniões para apresentação de projetos de financiamento, emissão de Cadastro Ambiental Rural (CAR) e Declaração de Aptidão ao Pronaf (DAP), doação de sementes e implantação de unidades demonstrativas individuais. Dentre esses serviços, o mais recorrente, de acordo com os agricultores, é o de orientação sobre financiamento, com a ressalva que os pacotes propostos nestes financiamentos em grande medida estão na contramão do que os agricultores 
estão produzindo, ou da aptidão agrícola local. A consequência desse processo de afastamento do Estado e diminuição da oferta de serviços públicos de ATER ao meio rural e à agricultura aparece, hoje, evidenciada pela comprovada insuficiência destes serviços em atender à demanda da agricultura familiar e dos demais povos que vivem e exercem atividades produtivas no meio rural, principalmente nas áreas de maior necessidade, como as regiões Norte e Nordeste (BRASIL, 2004).

A relação entre agricultores e agentes de ATER se apresenta como um estado de permanente expectativa, ora pelo atendimento não chegar a todos e haver um sentimento de diferenciação entre a prestação de serviço a um grupo, ora devido os agricultores se apresentarem como receptivos e interessados em compartilhar seus problemas e experiências com os agentes. Os agricultores, portanto, reclamam de não haver uma presença mais efetiva dos serviços de ATER na comunidade. E ao serem indagados quais eram os serviços mais comuns, os mesmos afirmaram desconhecer quaisquer atividades que lhes possam trazer algum benefício, sendo que eles se dizem completamente receptivos para receber os agentes. Segundo Caporal e Ramos (2006), a extensão rural pública deve priorizar a relação entre agricultores e agentes de ATER, criando novas possibilidades de resgate dos conhecimentos locais e de participação consciente nas mudanças necessárias nos níveis político, social, ambiental, econômico, cultural e ético. Além disso, deve estimular o estabelecimento de laços de solidariedade no meio rural.

Por este motivo, tornou-se importante verificar com as entidades de ATER, a existência de alguma dificuldade entre a conversa do técnico extensionista com o agricultor. As respostas variaram de acordo com as localidades, onde para alguns não existe dificuldade nenhuma na transmissão dos conhecimentos levados durante a ATER, para outros a resistência dos agricultores torna o trabalho difícil de ser executado, sendo a falta de regularização das terras também um assunto mencionado. Já para os agricultores entrevistados existem muitos entraves na conversa com os técnicos extensionistas, como ausência destes e falta de clarez̧a na transmissão das técnicas. Para os agricultores, a ausência sistemática do serviço de assistência técnica e extensão colabora para a não solução dos problemas, como por exemplo, a falta de instrução técnica para correção do solo, ou dificuldade em resolver problemas relacionados à baixa produtividade do solo ou do cultivo, a falta de conhecimento sobre a piscicultura, dificuldades de parcerias e financiamentos.

Estes resultados demonstram que a troca de conhecimentos e de saberes empíricos e científicos entre técnicos e agricultores deveria elaborar alternativas que lhes permitissem adequadas condições de vida local. Porque o objetivo 
da ação extensionista é promover condições para ajudar no fortalecimento da cidadania, na efetiva participação dos atores nas decisões e na melhoria da qualidade de vida das populações rurais (CAPORAL; RAMOS, 2006). Com a finalidade de minimizar estes problemas, a PNATER procura estabelecer que os novos profissionais extensionistas devem desempenhar um "papel educativo, atuando como animadores e facilitadores de processos de desenvolvimento rural sustentável" (BRASIL, 2004, p. 6).

O quadro de ausência dos serviços de ATER e a falta de conhecimento sobre ações que promovam a aproximação do Estado com as populações rurais demonstram a necessidade da busca de alternativas para que as comunidades possam ser assistidas e incluídas, haja vista que o estado do Amazonas possui ações e programas voltados aos serviços de ATER, mas que precisam contemplar as multidiversidades do agricultor observando as peculiaridades das diferentes cadeias produtivas. Assim, ao perguntarmos nas unidades locais o que efetivamente era possível fazer como ação de acordo com a PNATER, os mesmos informaram que o maior entrave para a realização de todos os serviços é o limitado orçamento, já que os municípios possuem dificuldades geográficas que necessitam de maiores recursos para locomoção, por exemplo.

No fim do DRP, foi solicitado aos agricultores que fizessem uma avaliação do que poderia ser melhorado pelos prestadores de serviços de ATER para que esta fosse mais eficiente. As respostas foram efetivamente referentes aos recursos humanos, ou seja, falta de técnicos para realizarem os trabalhos, além de mais visitas e esclarecimentos técnicos nas comunidades. Com o sancionamento da Lei $\mathrm{n}^{\mathrm{o}}$ 12.188 pelo governo federal, em 2010, as formas de contratação de serviços de ATER passaram a ser realizadas por meio de chamadas públicas, com dispensa de licitação, o que solucionou, em grande parte, os problemas burocráticos apresentados pelos convênios e contratos de repasse de recursos. Foi dado maior foco na qualidade das ações de ATER, aumentando o tempo do técnico no atendimento aos agricultores e às agricultoras, estabelecendo temas prioritários, e facilitando a continuidade do financiamento das ações de ATER (BRASIL, s/d).

As unidades locais de ATER escrevem e submetem propostas de acordo com os editais lançados por meio das chamadas públicas, a fim de serem contempladas com o orçamento dos mesmos para poder promover atividades que estejam de acordo com os princípios e diretrizes da PNATER. No ano de 2012 o município de Humaitá e Apuí atenderam as chamadas públicas realizadas pelo extinto Ministério do Desenvolvimento Agrário (MDA). De acordo com informações, 200 famílias foram contempladas com este serviço em cada um desses municípios, mas o município de Canutama não atendeu a chamada porque 
não se enquadrava dentro dos requisitos previstos no edital do MDA. Já no ano de 2013, Canutama e Humaitá atenderam a chamada pública, e Apuí não atendeu por não obter o perfil do edital.

É importante ressaltar que as chamadas públicas exerceram um grande papel para ATER de todo país, mas o recurso oferecido por meio destas não era suficiente para investir em uma ATER intensiva e inclusiva, no caso do Amazonas. No entanto, no estado do Amazonas a principal fonte de recurso para a prestação de serviço de ATER adivinha destas Chamadas, já que o orçamento anual do IDAM não chegava a cem mil reais anuais para a agricultura familiar, como pode ser verificado nos orçamentos anuais do órgão.

A pesquisa possibilitou, portanto, verificar que o desenvolvimento rural sustentável, com igualdade e equidade para as famílias agricultoras, como está previsto na PNATER, ainda é uma realidade distante no estado do Amazonas, uma vez que requer mudanças no papel do governo no que diz respeito a maiores investimentos na ATER, principalmente os investimentos estaduais.

\section{CONSIDERAÇÕES FINAIS}

Embora a Lei da Agricultura Familiar e a implementação da PNATER tenham representado um marco e uma conquista para os agricultores familiares, e políticas como o PRONAF e as compras governamentais (PAA e PNAE) também terem representado um avanço, já que respectivamente tentaram suprir as deficiências de um dos maiores gargalos para os pequenos produtores e facilitar o acesso ao crédito, muito ainda precisa ser feito para que o grupo social deixe de ser marginalizado e rotulado como atrasado.

A PNATER estabelece como público da ATER a agricultura familiar, considerando a sua diversidade e as desigualdades, além de incluir a questão da sustentabilidade nas dimensões econômica, social e ambiental, e a participação e acesso às políticas públicas, como forma de promover o desenvolvimento rural sustentável. Não há o que questionar que os avanços conquistados ao longo dos anos são muitos, apesar das políticas de inclusão e a própria PNATER serem recentes, considerando o processo histórico de desenvolvimento do país (BRASIL, s/d). Entretanto, apesar do agricultor familiar das áreas estudadas apresentarem perfil para serem contemplados com este novo modelo de ATER, estes ainda não o são, pois no que tange à execução, esta ainda é uma política excludente já que não é acessível a todos. Neste sentido, ainda existem muitos desafios na construção de um novo modelo de desenvolvimento rural, principalmente nas áreas pesquisadas. 
Diante da realidade apresentada, no universo das entrevistas feitas com as unidades locais de ATER e com os respectivos agricultores, foi possível concluir que a adoção de um novo modelo de desenvolvimento pelo Brasil, e a consequente criação e ampliação de políticas públicas voltadas para a inclusão e a promoção do desenvolvimento rural sustentável, requerem ainda grandes mudanças na formação dos profissionais de ATER e nas entidades de ATER, que permitam o desenvolvimento e a adoção de abordagens e métodos de ATER orientados pela PNATER. Ou seja, que extensionistas ou agentes sejam facilitadores do acesso às informações e animadores do processo de conhecimento de forma adequada para a diversidade da agricultura familiar.

É necessário também a criação de mecanismos que permitam à ATER atuar de forma integrada com os governos federal, estadual e municipal, visando harmonizar e potencializar as diferentes políticas setoriais no rural. O acesso às políticas públicas para o rural passa por uma ação organizada e focada dos gestores municipais em parceria com o serviço de extensão rural. A ampliação da estrutura dos serviços de ATER para que possa promover a apropriação das políticas públicas pelo universo da agricultura familiar e da reforma agrária é outro gargalo identificado. Neste sentido, esta pesquisa buscou contribuir nas discussões que chamem a atenção do poder público, para que estes tomem providências a fim de garantir uma ATER de qualidade e quantidade suficiente, visando o fortalecimento da agricultura familiar, como prevê a PNATER.

\section{REFERÊNCIAS}

BARDIN, Laurence. Análise de conteúdo. Lisboa: Edições 70, LDA, abril de 2007.

BRASIL. Ministério do Desenvolvimento Agrário. SAF. DATER. Política Nacional de Assistência Técnica e Extensão Rural. Brasília, 2004. Ministério do Desenvolvimento Agrário. CONDRAF. $1^{\text {a }}$ Conferência Nacional sobre Assistência Técnica e Extensão Rural. ATER para Agricultura Familiar e Reforma Agrária e o Desenvolvimento Sustentável do Brasil Rural. Brasília, s/d.

CAPORAL, F. R.; RAMOS, L. F. Da Extensão Rural Convencional à Extensão Rural para o desenvolvimento sustentável: enfrentar desafios para romper a inércia. Brasília, 2006. 3p.

CAPORAL, F. R. Política Nacional de ATER: primeiros passos de sua implementação e alguns obstáculos e desafios a serem enfrentados. Brasília, 2005. 9-27p. 
CASTRO, C. E. F. de. A Pesquisa em Agricultura Familiar. In: CASTRO, et. al. Pontes para o Futuro. 1 ed. Campinas-SP: CONSEPA, 2005. p. 7-48.

CORDEIRO, M. S. S. O recebimento do título definitivo em assentamentos: discursos acerca da propriedade da terra. In: CONGRESSO BRASILEIRO DE SOCIOLOGIA, 15. Curitiba, 2011. Anais... Curitiba, 2011

COSTA, Francimara Souza da. A dinâmica dos recursos comuns em unidades de conservação e assentamentos rurais no Amazonas: uma abordagem fuzzy. 2014. 363f. Tese (Doutorado em Desenvolvimento Sustentável do Trópico Úmido) - Núcleo de Altos Estudos Amazônicos, Universidade Federal do Pará, Belém, 2014.

COSTA, R. Comercialização e transformação dos produtos da agricultura familiar: alguns pontos a discutir. In: KÜSTER, Angela; MARTÍ, Jaime Ferré (Org). Agricultura familiar, agroecologia e mercado no Norte e Nordeste do Brasil. Fortaleza: Fundaçao Konrad Adenauer; DED, 2004. p. 67-74.

FRAXE, Therezinha de Jesus Pinto. Cultura cabocla-ribeirinha: mitos, lendas e transculturalidade. 1. ed. São Paulo: Annablume Editora, 2004. 374 p.

FRAXE, Therezinha de Jesus Pinto; CASTRO, Albejamere Pereira de; SANTIAGO, Jozane Lima; WITKOSKI, Antônio Carlos. Extensão Rural e Desenvolvimento Sustentável no Amazonas. In: Agroecologia, Extensão Rural e Sustentabilidade na Amazônia. Manaus: UFAM, 2008. p. 24.

FRAXE, Therezinha de Jesus Pinto; PEREIRA, Henrique dos Santos; WITKOSKI, Antônio Carlos. Comunidades ribeirinhas amazônicas: modo de vida e uso dos recursos naturais. 1. ed. Manaus: Reggo Edições, 2011. 224 p.

MATOS, G. R.; MARIN, J. O. B. Agricultores familiares e sistemas de produção de frutas em Itapuranga, Goiás. Pesq. Agropec. Trop., Goiânia, v. 39, n. 3, p. 197-206, jul./set. 2009

MEDEIROS, K. F; A Política Nacional de Assistência Técnica e Extensão Rural - PnATER: uma abordagem da realidade das Unidades Produtivas Familiares - UPF's na comunidade Carneira no município de Junco do Seridó/ PB. 2012. Trabalho de Conclusão de Curso (Gestão Pública Municipal) Universidade Federal da Paraíba, João Pessoa, 2012.

MONTEIRO, S. T. Anotações por uma história rural do médio Amazonas. Manaus: EMATER-AM, 1981. 96 p. 
NEIVA, Ana Cláudia Gomes Rodrigues. Caracterização socioeconômica da comunidade quilombola Kalunga e proposta de reintrodução do bovino curraleiro como alternativa de geração de renda. 2009. 138f. Tese (Doutorado em Ciência Animal) - Escola de Veterinária, Universidade Federal de Goiás, Goiânia, 2009.

OLIVEIRA, A. D. S de; MAYORGA, M. I de. O. Os impactos da participação do atravessador na economia do setor agrícola: um estudo de caso. In: CONGRESSO DA SOBER, 43. - "Instituições, Eficiência, Gestão e contratos no Sistema Agroindustrial.” Ribeirão Preto-SP, 2005. Anais... Ribeirão Preto-SP, 2005.

PEIXOTO, M. Extensão rural no Brasil - uma abordagem histórica da legislação. Brasília: Consultoria Legislativa do Senado Federal, out. 2008. (Série Textos para Discussão, n. 48. ISSN 1983-0645). Disponível em: <https:// www12.senado.leg.br/publicacoes/estudos-legislativos/tipos-de-estudos/ textos-para-discussao/td-48-extensao-rural-no-brasil-uma-abordagem-historicada-legislacao>. Acesso em: 13/12/2017

PETTAN, K. B. As inter-relações pesquisa, ensino e extensão. In: CASTRO, C. E. F. et al. Ponte para o futuro. Campinas-SP: CONSEPA, 2005. p. 49-64.

SCHULTZ, Theodore W. A transformação da agricultura tradicional. Connecticut, EUA, 1964.

VERDEJO, M. E. Diagnóstico Rural Participativo: Guia Prático DRP. Brasília: MDA/ Secretaria da Agricultura Familiar, 2006. 
